\title{
Self-reported adherence to pharmacotherapy in cancer patients
}

\section{Shakeel Ahmad Mir ${ }^{1 *}$, Mehraj Ud-Din Bhat ${ }^{2}$, Danish Shakeel ${ }^{3}$}

${ }^{1}$ Department of Clinical Pharmacology, ${ }^{2}$ Department of Clinical Hematology, Sher-I-Kashmir Institute of Medical Sciences, Srinagar, Kashmir, India

${ }^{3}$ Department of Computer Sciences and Engineering, University Institute of Engineering, Chandigarh University, Mohali, Punjab, India

Received: 09 March 2020

Revised: 13 April 2020

Accepted: 16 April 2020

\section{*Correspondence:}

Dr. Shakeel Ahmad Mir,

Email: drshakeelahmadmir@gmail.com

Copyright: (C) the author(s), publisher and licensee Medip Academy. This is an open-access article distributed under the terms of the Creative Commons Attribution Non-Commercial License, which permits unrestricted non-commercial use, distribution, and reproduction in any medium, provided the original work is properly cited.

\begin{abstract}
Background: Medication adherence is a challenging issue. Non-adherence has been found to be associated with increased healthcare costs. Pharmacological anticancer therapies are increasingly shifting to oral medications. Oral therapy is more convenient and easier to administer but various issues are related to oral anticancer therapy, the prominent one being adherence.

Methods: Single group, non-randomized, self-report study conducted from December, 2019 to February, 2020 in SKIMS Hospital, Kashmir. A novel medication adherence scale, General Medication Adherence Scale (GMAS) was used to assess the adherence.

Results: The study population consists of $58.7 \%$ males and $41.3 \%$ females. $54.7 \%$ patients were illiterate and $45.3 \%$ patients were literate. $13.3 \%$ patients received one drug, $14.7 \%$ two drugs, $40.0 \%$ three drugs, and $32.0 \%$ received more than three drugs. $13.3 \%$ patients had poor, $9.3 \%$ low, $42.7 \%$ partial, $12.0 \%$ good and $22.7 \%$ high adherence. In low income group, $6.7 \%$ patients had poor, $6.7 \%$ low, $13.3 \%$ partial, $26.7 \%$ good and $46.7 \%$ high adherence. Among middle income group, $10.0 \%$ patients had poor, $10.0 \%$ low, $53.3 \%$ partial, $10.0 \%$ good and $16.7 \%$ high adherence. In high income group, $20.0 \%$ patients had poor, $10.0 \%$ low, $46.7 \%$ partial, $6.7 \%$ good and $16.7 \%$ high adherence.

Conclusions: Most of the cancer patients were partially adherent to the prescribed medication. Various associated factors were gender, socio-economic status, literacy, and place of residence. Considerable variation in adherence was found in this study.
\end{abstract}

Keywords: Adherence, Cancer, GMAS tool, Oral anticancer drugs

\section{INTRODUCTION}

Cancer is the second leading cause of death globally and was responsible for an estimated 9.6 million deaths in 2018. Approximately $70 \%$ of deaths from cancer occur in low- and middle-income countries. ${ }^{1}$ About 606,880 Americans were estimated to die of cancer in $2019 .^{2}$ The estimated number of cancer cases in India increased from 548,000 in 1990 to $1,069,000$ in $2016 .^{3}$
Pharmacologic anticancer therapies are increasingly shifting to orally administered drugs. ${ }^{4}$ Compared to parenteral therapies, oral anticancer therapies offer convenience, and are preferred by patients. The availability of oral anticancer drugs has drastically risen in recent years. With the rise in availability and increasing use, concerns about adherence have become an important issue. $^{5}$ 
Medication adherence is defined by the World Health Organization as "the extent to which a person`s behaviortaking medication, following a diet and/or executing life style changes, corresponds with agreed recommendations from a healthcare provider. ${ }^{6}$ There are currently no standard protocols for ensuring adherence to oral anticancer agents at home. Although patients with cancer exhibit higher motivation towards medication adherence, yet the reports on adherence and persistence among patients with cancer show that adherence ranges from $16 \%$ to $100 \%$, depending on the type of therapy and the methods of measurement used. ${ }^{7}$

Adherence problems have generally been overlooked and have received little attention. Even the most motivated patient can have difficulties in taking medications exactly as prescribed by the doctor. The aim of the present study was to assess the medication adherence in cancer patients and to analyze various factors affecting it.

\section{METHODS}

This is a prospective, single group, observational study conducted from December, 2019 to February, 2020.

A validated demographics questionnaire was prepared in English. It had two sections. Section one had the questions about the general demographic information such as age, gender, place of residence, qualification, economic status etc. Section two asked the questions related to medication adherence. We used the English version of a novel medication adherence tool known as GMAS (General Medication Adherence Scale). ${ }^{8}$

75 patients with documented cancer, attending the OPD of SKIMS Hospital, Kashmir, were enrolled in a single group, non-randomized self-report study. Patients who were taking at least one oral anticancer agent at their homes were included in the study. Most of the patients were also taking drugs for other co-morbidities. Those who were illiterate and could not fill up the questionnaire were helped by their attendants. Authors collected the information about the type of cancer, duration of illness, oral antineoplastic drugs, concurrent medication, besides other demographic characteristics.

\section{Inclusions criteria}

Age more than 12 years, suffering from documented cancer, those willing to participate in the study, domestic therapy with at least one oral anticancer drug in the treatment schedule were included.

\section{Exclusion criteria}

Age less than 12 years, non-cancerous disease, those not willing to participate in the study, under directly observed oral or parenteral anticancer therapy were excluded.
The objectives of the study were explained to the study participants prior to data collection, and their consents were sought and the questionnaires were given only to those who agreed. The confidentiality of the responders was maintained.

\section{Statistical analysis}

Analysis was done by combination of manual calculators, VassarStats and online statistical calculators. Differences in adherence rates based on patient characteristics were examined.

\section{RESULTS}

Demographic details of the studied population shows in Table 1 . The study population consists of $58.7 \%(n=44)$ males and $41.3 \%(n=31)$ females. There were $1.3 \%(n=1)$ patients in the age group of $11-20$ years, $4.0 \%(n=3) 21-30$ years, $21.3 \% \quad(n=16) 31-40$ years, $28.0 \% \quad(n=21) 41-50$ years, $17.3 \%(n=13)$ 51-60 years, $20.0 \%(n=15) 61-70$ years, and $8.0 \%(n=6)>70$ years. $54.7 \%(n=41)$ patients were illiterate and $45.3 \%(n=34)$ patients were literate. $73.5 \%(n=25)$ had studied up to school level, $14.7 \%(n=5)$ up to college level and $11.8 \%(n=4)$ up to university level. $22.7 \%(n=17)$ patients were from urban areas, $68.0 \%$ $(\mathrm{n}=51)$ from rural areas, and $9.3 \%(\mathrm{n}=7)$ from cities.

Table 1: Characteristics of study population.

\begin{tabular}{|lll|}
\hline Demographic & N & $\%$ \\
\hline Sex & & \\
\hline Male & 44 & 58.7 \\
\hline Female & 31 & 41.3 \\
\hline Age (in years) & & \\
\hline $0-10$ & 0 & 0.0 \\
\hline $11-20$ & 1 & 1.3 \\
\hline $21-30$ & 3 & 4.0 \\
\hline $31-40$ & 16 & 21.3 \\
\hline $41-50$ & 21 & 28.0 \\
\hline $51-60$ & 13 & 17.3 \\
\hline $61-70$ & 15 & 20.0 \\
\hline$>70$ & 6 & 8.0 \\
\hline Educational status & & \\
\hline Literate & 34 & 45.3 \\
\hline School Level & 25 & 73.5 \\
\hline College Level & 5 & 14.7 \\
\hline University Level & 4 & 11.8 \\
\hline Illiterate & 41 & 54.7 \\
\hline Area of residence & & \\
\hline Rural & 51 & 68.0 \\
\hline Urban & 17 & 22.7 \\
\hline City & 7 & 9.3 \\
\hline
\end{tabular}

Table 2 shows medication behaviour. 13.3\% $\quad(n=10)$ patients were prescribed one drug, $14.7 \%(\mathrm{n}=11)$ two drugs, $40.0 \%(n=30)$ three drugs, and $32.0 \%(n=24)$ more than 3 drugs. $21.3 \%(n=16)$ patients were taking drugs for less than one year, $28.0 \%(\mathrm{n}=21)$ for $1-2$ years, $14.7 \%$ $(\mathrm{n}=11)$ for $2-3$ years, $22.7 \%(\mathrm{n}=17)$ for $3-4$ years and $13.3 \%(n=10)$ for more than 4 years. 
Table 2: Medication behaviour.

\begin{tabular}{|c|c|c|}
\hline Medication & $\mathbf{N}$ & $\%$ \\
\hline \multicolumn{3}{|c|}{ Number of drugs prescribed } \\
\hline One drug & 10 & 13.3 \\
\hline 2 drugs & 11 & 14.7 \\
\hline 3 drugs & 30 & 40.0 \\
\hline$>3$ drugs & 24 & 32.0 \\
\hline \multicolumn{3}{|c|}{ Treatment duration (in years) } \\
\hline$<1$ & 16 & 21.3 \\
\hline $1-2$ & 21 & 28.0 \\
\hline $2-3$ & 11 & 14.7 \\
\hline $3-4$ & 17 & 22.7 \\
\hline$>4$ & 10 & 13.3 \\
\hline
\end{tabular}

Adherence level (as per GMAS). 13.3\% $(\mathrm{n}=10)$ had poor, 9.3\% $(\mathrm{n}=7)$ low, $42.7 \%(\mathrm{n}=32)$ partial, $12.0 \%(\mathrm{n}=9)$ good and $22.7 \%(n=17)$ high adherence level. $6.8 \%(n=3)$ males had poor, 9.1\% $(\mathrm{n}=4)$ low, $45.4 \%(\mathrm{n}=20)$ partial, $9.1 \%$ $(n=4)$ good and 29.5\% $(n=13)$ high adherence level. 22.6\% $(n=7)$ females had poor, 9.7\% $(n=3)$ low, 38.7\% $(n=12)$ partial, $16.1 \%(n=5)$ good and $12.9 \%(n=4)$ high adherence (Table 3).

In this study $100 \%$ patients $(n=1)$ in the age group of 11 20 years had good adherence. In the age group of 21-30 years, 33.3\% $(n=1)$ had each low, partial and high adherence. In the age group of 31-40 years, $12.5 \%(\mathrm{n}=2)$ had poor, $18.7 \%(n=3)$ low, $25.0 \%(n=4)$ partial, $25.0 \%$ $(n=4)$ good and $18.7 \%(n=3)$ high adherence. In the age group of $41-50$ years, $19.0 \%(n=4)$ had poor, $4.8 \%(n=1)$ low, $52.4 \%(\mathrm{n}=11)$ partial, $9.5 \%(\mathrm{n}=2)$ good and $14.3 \%$ $(\mathrm{n}=3)$ high adherence. In the age group of 51-60 years, $30.8 \%(n=4)$ had poor, $7.7 \%(n=1)$ low, $30.8 \% \quad(n=4)$ partial, and $30.8 \%(\mathrm{n}=4)$ high adherence. In the age group of $61-70$ years, $6.7 \%(n=1)$ had low, $53.3 \%(n=8)$ partial, $6.7 \%(n=1)$ good and $33.3 \%(n=5)$ high adherence. In patients above 70 years, $66.7 \%(n=4)$ had partial, $16.7 \%$ $(\mathrm{n}=1)$ good and $16.7 \%(\mathrm{n}=1)$ high adherence.

Table 3: Observed adherence in study population by GMAS.

\begin{tabular}{|lll|}
\hline Level & $\mathbf{N}$ & $\%$ \\
\hline Overall adherence level & & \\
\hline Poor & 10 & 13.3 \\
\hline Low & 7 & 9.3 \\
\hline Partial & 32 & 42.7 \\
\hline Good & 9 & 12.0 \\
\hline High & 17 & 22.7 \\
\hline Gender-wise adherence level & \\
\hline Males & & \\
\hline Poor & 3 & 6.8 \\
\hline Low & 4 & 9.1 \\
\hline Partial & 20 & 45.4 \\
\hline Good & 4 & 9.1 \\
\hline High & 13 & 29.5 \\
\hline Females & & \\
\hline Poor & 7 & 22.6 \\
\hline Low & 3 & 9.7 \\
\hline Partial & 12 & 38.7 \\
\hline Good & 5 & 16.1 \\
\hline High & 4 & 12.9 \\
\hline
\end{tabular}

Table 4: Adherence level as per age, qualification, economic status, and area of residence.

\begin{tabular}{|c|c|c|c|c|c|}
\hline Age-wise GMAS score & \multicolumn{5}{|c|}{ Adherence level (GMAS) } \\
\hline \multirow{2}{*}{ Age group (in years) } & Poor & Low & Partial & Good & High \\
\hline & $\mathbf{N}(\%)$ & $\mathbf{N}(\%)$ & $\mathbf{N}(\%)$ & $\mathbf{N}(\%)$ & $\mathbf{N}(\%)$ \\
\hline $0-10$ & 0 & 0 & 0 & 0 & 0 \\
\hline $11-20$ & 0 & 0 & 0 & $1(100)$ & 0 \\
\hline $21-30$ & 0 & $1(33.3)$ & $1(33.3)$ & 0 & $1(33.3)$ \\
\hline $31-40$ & $2(12.5)$ & $3(18.7)$ & $4(25.0)$ & $4(25.0)$ & $3(18.7)$ \\
\hline $41-50$ & $4(19.0)$ & $1(4.8)$ & $11(52.4)$ & $2(9.5)$ & $3(14.3)$ \\
\hline $51-60$ & $4(30.8)$ & $1(7.7)$ & $4(30.8)$ & 0 & $4(30.8)$ \\
\hline $61-70$ & 0 & $1(6.7)$ & $8(53.3)$ & $1(6.7)$ & $5(33.3)$ \\
\hline$>70$ & 0 & 0 & $4(66.7)$ & $1(16.7)$ & $1(16.7)$ \\
\hline \multicolumn{6}{|c|}{ Educational level-wise adherence level (GMAS) } \\
\hline \multicolumn{6}{|l|}{ Qualification } \\
\hline Illiterate & $8(19.5)$ & $3(7.3)$ & $19(46.3)$ & $3(7.3)$ & $8(19.5)$ \\
\hline Literate & $2(5.9)$ & $4(11.8)$ & $13(38.2)$ & $6(17.6)$ & $9(26.5)$ \\
\hline \multicolumn{6}{|c|}{ Economic status-wise adherence level (GMAS) } \\
\hline Low income group & $1(6.7)$ & $1(6.7)$ & $2(13.3)$ & $4(26.7)$ & $7(46.7)$ \\
\hline Middle income group & $3(10.0)$ & $3(10.0)$ & $16(53.3)$ & $3(10.0)$ & $5(16.7)$ \\
\hline High income group & $6(20.0)$ & $3(10.0)$ & $14(46.7)$ & $2(6.7)$ & $5(16.7)$ \\
\hline \multicolumn{6}{|c|}{ Area of residence wise adherence level (GMAS) } \\
\hline Rural & $10(19.6)$ & $7(13.7)$ & $21(41.2)$ & $5(9.8)$ & $8(15.7)$ \\
\hline Urban & 0 & 0 & $8(47.1)$ & 3 (17.6) & $6(35.3)$ \\
\hline City & 0 & 0 & 3 (42.9) & $1(14.2)$ & 3 (42.9) \\
\hline
\end{tabular}


Table 5: Adherence level-number of prescribed drugs.

\begin{tabular}{|c|c|c|c|c|c|}
\hline \multirow{3}{*}{ No. of drugs } & \multicolumn{5}{|c|}{ Adherence Level (GMAS) } \\
\hline & Poor & Low & Partial & Good & High \\
\hline & $\mathbf{N}(\%)$ & $\mathbf{N}(\%)$ & $\mathbf{N}(\%)$ & $\mathbf{N}(\%)$ & $\mathbf{N}(\%)$ \\
\hline One drug & $1(10.0)$ & $2(20.0)$ & $3(30.0)$ & $1(10.0)$ & $3(30.0)$ \\
\hline Two drugs & $2(18.2)$ & $1(9.1)$ & $4(36.4)$ & $1(9.1)$ & $3(27.3)$ \\
\hline Three drugs & $4(13.3)$ & $3(10.0)$ & $14(46.7)$ & $4(13.3)$ & $5(16.7)$ \\
\hline$>3$ drugs & $3(12.5)$ & $1(4.2)$ & $11(45.9)$ & $3(12.5)$ & $6(25.0)$ \\
\hline
\end{tabular}

$19.5 \%(n=8)$ illiterate patients had poor, $7.3 \%(n=3)$ low, $46.3 \%(n=19)$ partial, $7.3 \%(n=3)$ good and $19.5 \%(n=8)$ high adherence. $5.9 \%(\mathrm{n}=2)$ literate patients had poor, $11.8 \%(\mathrm{n}=4)$ low, $38.2 \%(\mathrm{n}=13)$ partial, $17.6 \%(\mathrm{n}=6)$ good and $26.5 \%(n=9)$ high adherence.

In this study $6.7 \%(\mathrm{n}=1)$ patients in low income group had each poor, and low adherence, $13.3 \%(\mathrm{n}=2)$ partial, $26.7 \%$ $(n=4)$ good and $46.7 \%(n=7)$ high adherence. Among middle income group, $10.0 \%(\mathrm{n}=3)$ patients had each poor, and low adherence, 53.3\% $(\mathrm{n}=16)$ partial, $10.0 \%(\mathrm{n}=3)$ good and $16.7 \%(\mathrm{n}=5)$ high adherence. $20.0 \% \quad(\mathrm{n}=6)$ patients in high income group had poor, $10.0 \%(\mathrm{n}=3)$ low, $46.7 \%(n=14)$ partial, $6.7 \%(n=2)$ good and $16.7 \%(n=5)$ high adherence (Table 4 ).

In patients receiving one drug, $10.0 \%(\mathrm{n}=1)$ had poor, $20.0 \%(n=2)$ low, $30.0 \%(n=3)$ partial, $10.0 \%(n=1)$ good and $30.0 \%(n=3)$ high adherence. In those receiving two drugs, $18.2 \%(n=2)$ had poor, $9.1 \%(n=1)$ low, $36.4 \%$ $(n=4)$ partial, 9.1\% $(n=1)$ good and $27.3 \%(n=3)$ high adherence. Among the patients receiving three drugs, $13.3 \%(n=4)$ had poor, $10.0 \%(n=3)$ low, $46.7 \%(n=14)$ partial, $13.3 \% \quad(n=4)$ good and $16.7 \% \quad(n=5)$ high adherence. Patients receiving more than 3 drugs had, $12.5 \%(\mathrm{n}=3)$ poor, $4.2 \%(\mathrm{n}=1)$ low, $45.9 \%(\mathrm{n}=11)$ partial, $12.5 \%(n=3)$ good, and $25.0 \%(n=6)$ high adherence (Table 5).

\section{DISCUSSION}

Despite evidence indicating therapeutic benefit for adhering to a prescribed regimen, many patients do not take their medications as prescribed. Non-adherence often leads to morbidity and to higher health care costs. ${ }^{9}$ Poor adherence to the treatment of chronic diseases is a worldwide problem of striking magnitude. It has been found that approximately $50 \%$ of the patients do not adhere to one of their chronic medications. ${ }^{6}$ Poor adherence to long term therapies severely compromises the effectiveness of treatment.

In the present study, most of the cancer patients had partial adherence to their prescribed medications which included at least one oral anticancer drug. Only $34.7 \%$ showed good to high adherence. Male patients had better adherence as compared to female patients but the correlation between gender and the medication adherence was statistically insignificant $(p>0.05)$. Majority of age groups showed partial adherence. Only the age groups 21-30 years and 6170 years had a better percentage of high adherence. The correlation between age and medication adherence was statistically insignificant $(p>0.05)$. Literate patients had better and significant good to high adherence $(\mathrm{p}=0.05)$. Middle and high income groups had better adherence as compared to low income groups and the correlation between economical status and adherence was statistically significant $(\mathrm{p}<0.05)$. As compared to other groups, patients belonging to rural areas had poor adherence. Authors found varying but statistically insignificant $(p>0.05)$ association between number of drugs prescribed and adherence.

In a systemic review of factors influencing adherence to cancer treatment in older adults with cancer, the adherence rate found was $52 \%$ to $100 \% .^{10}$

A systemic review of adherence to oral antineoplastic therapies, found that adherence rates varied widely, from $46 \%$ to $100 \%$, depending on patient sample, medication type, follow-up period, assessment measure, and calculation of adherence. ${ }^{11}$

In another review mainly on hormone based and targeted anticancer therapies, adherence rates were found to vary from $14 \%$ to $100 \% .^{12}$

The validity of our findings relies primarily on the accuracy of responses. Authors tried to minimize recall bias by a using a well-structured pre-validated questionnaire. Another limitation of this study is the limited sample size. The design of the study does not ensure that the study population is representative of all cancer patients in the region. The present study is only exploratory in nature. There is a need to conduct large scale studies to reach a definitive conclusion.

\section{CONCLUSION}

Medication adherence is crucial for the success of pharmacotherapy in any disease. Medication nonadherence is a complex issue. Majority of the cancer patients were having partial adherence to prescribed drugs. Almost all the patients cited medication toxicity and outof pocket drug cost as major causes of non- or pooradherence. 


\section{ACKNOWLEDGEMENTS}

The authors would like to express their sincere thanks and gratitude to Dr. Atta Abbas Naqvi and Professor Mohamed Azmi Hassali, of Discipline of Social and Administrative Pharmacy, School of Pharmaceutical Sciences, Universiti Sans Malaysia (USM), Penang, Malaysia, for allowing to use GMAS medication adherence tool in this study. The authors also wish to thank the patients who participated in the study.

Funding: No funding sources

Conflict of interest: None declared

Ethical approval: The study was approved by the Institutional Ethics Committee

\section{REFERENCES}

1. World Health Organization (2018). Cancer. Available at: https://www.who.int/news-room/fact-sheets/detail/ cancer. Accessed on 2 January 2020.

2. American Cancer society. (2019). Cancer facts and figures. Available at: https://www.cancer.org/content/ dam/cancer-org/research/cancer-facts-and-statistics/ annual-cancer-facts-and-figures/2019/cancer-factsand-figures-2019.pdf. Accessed on 2 January 2020.

3. Dhillon PK, Mathur P, Nandakumar A, Fitzmaurice C, Kumar GA, Mehrotra R, et al. The burden of cancers and their variations across the states of India: The Global Burden of Disease Study 1990-2016. Lancet Oncol. 2018;19:1289-306.

4. Paolella GA, Boyd AD, Wirth SM, Cuellar S, Venepalli NK, Crawford SY. Adherence to oral anticancer medications: evolving interprofessional roles and pharmacist workforce considerations. Pharmacy. 2018;6(1):23.
5. Partridge AH, Avorn J, Wang PS, Winer EP. Adherence to therapy with oral antineoplastic agents. J Nat Cancer Instit. 2002;94(9):652-61.

6. World Health Organization, 2003. Adherence to longterm therapies: Evidence for action. Geneva: World Health Organization. Available at: http://apps.who.int/ medicinedocs/pdf/s4883e/s4883e.pdf. Accessed on 2 January 2020.

7. Foulon V, Schöffski P, Wolter P. Patient adherence to oral anticancer drugs: an emerging issue in modern oncology. Acta Clin Belg. 2011;66(2):85-96.

8. Naqvi AA, Hassali MA, Rizvi M, Zehra A, Iffat W, Haseeb A, Jamshed S. Development and validation of a novel General Medication Adherence Scale (GMAS) for chronic illness patients in Pakistan. Frontier Pharmacol. 2018;9:1124.

9. Rolnick SJ, Pawloski PA, Hedblom BD, Asche SE, Bruzek RJ. Patient characteristics associated with medication adherence. Clini Medi Res. 2013;11(2):54-65.

10. Puts MT, Tu HA, Tourangeau A, Howell D, Fitch M, Springall E, et al. Factors influencing adherence to cancer treatment in older adults with cancer: a systematic review. Ann Oncol. 2014;25(3):564-77.

11. Greer JA, Amoyal N, Nisotel L, Fishbein JN, MacDonald J, Stagl J, et al. A systematic review of adherence to oral antineoplastic therapies. Oncologist. 2016;21(3):354-76.

12. Barillet M, Prevost V, Joly F, Clarisse B. Oral antineoplastic agents: how do we care about adherence? $\mathrm{Br} \quad \mathrm{J}$ Clini Pharmacol. 2015;80(6):1289-302.

Cite this article as: Mir SA, Bhat MU, Shakeel D. Self-reported adherence to pharmacotherapy in cancer patients. Int J Basic Clin Pharmacol 2020;9:854-8. 